Original Article

\title{
Association of Diabetic Retinopathy with Diabetic Foot in a Tertiary Care Centre
}

\author{
Debnath $\mathrm{PR}^{1^{*}}$, Mohammuddunnobi ${ }^{2^{*}}$
}

\begin{abstract}
Diabetic retinopathy $(D R)$ is one of the most common causes of blindness in developed countries.

Objective: Early detection of diabetic retinopathy $(D R)$ is crucial for preventing irreversible blindness. A cross-sectional study was carried out at Department of Ophthalmology and Surgery, BIRDEM General Hospital, Dhaka from January 2017 to September 2017. Patients were included, who were known diabetic. New cases of type-2 diabetes were also included because they might have complications at the time of diagnosis because of the nature of disease. Mean duration of diabetes was significantly higher in DFU with DR group. $B U N$ and diabetes retinopathy were statistically significant $(p<0.05)$ between two groups. Mean HbAlc, pre-prandial glucose, C-peptide, cholesterol, triglyceride, HDL, LDL, hematocrit, creatinine, $A B I, T B I$ and $D M$ foot ulcer were not statistically significant $(p>0.05)$ between two groups. Most patients (33.3\%) had a grade I ulcer in DF with DR group and $33.3 \%$ in DF without DR group. Medication taking was significantly high patients who were $D F$ without $D R$. Combined agents was 11(36.7\%) and 11(36.7\%) in DF with $D R$ and $D F$ without $D R$ group respectively. Insulin was taken 16(53.3\%) in DF with DR group and 19(63.3\%) in $D F$ without DR group. Maximum patients had a grade I ulcer in diabetes foot ulcer. Medication taking was significantly high patients who were diabetes foot ulcer than without diabetes foot ulcer. Mean insulin, BUN and diabetes retinopathy was found statistically significantly higher in diabetes with diabetes foot ulcer.
\end{abstract}

Conclusion: Mean insulin BUN and diabetic retinopathy was was significantly higher in diabetes with diabetes foot ulcer.

Key ward : Diabetes foot ulcer, diabetes retinopathy, type 2 diabetes.

(Both authors are equally contributed)

1. Dr. Purabi Rani Debnath, Associate Prof. of ophthalmology \& Unit Head, BIRDEM, Dhaka. Email: debnathpurabi@yahoo.com.

2. Dr. Mohammuddunnobi, Resident Surgeon, BIRDEM, Dhaka. Email: drskfiroz2005@yahoo.com

*For correspondence

\section{INTRODUCTION}

Diabetes mellitus (DM) is the most common endocrine disorder in the world and is known to affect $8.3 \%$ of the population. ${ }^{1}$ Diabetic retinopathy (DR) is one of the most common causes of blindness in developed countries. ${ }^{2}$ Early detection of diabetic retinopathy (DR) is crucial for preventing irreversible blindness. The prevalence of retinopathy in diabetic inpatients was significantly higher than in an outpatient population and one quarter of inpatients with diabetes were noted to have previously undiagnosed retinopathy. ${ }^{3}$ Evidence indicates that with timely diagnosis and appropriate care, $50-70 \%$ of vision loss from diabetes can be prevented. ${ }^{4}$ Diabetes is one of the foremost causes of death in many countries and a leading cause of blindness, renal failure, and non traumatic amputation. Diabetes is also associated with numerous complications such as retinopathy, nephropathy, and neuropathy. 5

\section{MATERIAL AND METHODS}

A cross-sectional study was carried out Department of ophthalmology and Surgery, BIRDEM General Hospital, Dhaka from January 2017 to September 2017. Patients were included, who were known diabetic. New cases of type-2 diabetes were also included because they might have complications at the time of diagnosis because of the nature of disease. For type-1 diabetics, only those patients were selected who have duration of diabetes of more than five years, because in type- 1 diabetics complications usually starts after five years of duration, in accordance to the criteria of American Diabetes Association. Digital fundus photographs of the posterior pole were taken of each eye after pharmacological dilation. Presence, absence and severity of diabetic retinopathy and macular edema were graded on the basis of internationally accepted criteria. An investigator administered questionnaire and review of the medical record were used to obtain data about patient demographics, clinical characteristics and barriers to ophthalmic care. The association between these data and the presence of diabetic retinopathy was tested.

\section{RESULTS}

Out of 60 patients, the mean age was found $56.6 \pm 9.3$ years in DF (Diabetic foot) with DR (Diabetic retinopathy) group and $54.8 \pm 10.1$ years in DF without DR group. Male was predominant in both groups ( $73.3 \%$ vs $67.4 \%$ respectively). 
Mean duration of diabetes was significantly higher in DF with DR group $(\mathrm{p}<0.05)$. In both groups majority patients had history of HTN (76.6\% vs $73.3 \%)$. Mean systolic and diastolic blood pressure and BMI were not statistically significant ( $p>0.05)$ between two groups. History of smoking was found $10(33.3 \%)$ in DF with DR group and $12(40 \%)$ in DF without DR group. Which was not statistically significant $(p>0.05)$ between two groups (Table 1).

Mean insulin, BUN and diabetes retinopathy were statistically significant $(\mathrm{p}<0.05)$ between two groups. Mean HbA1c, pre-prandial glucose, C-peptide, cholesterol, triglyceride, HDL, LDL, hematocrit, creatinine, $\mathrm{ABI}, \mathrm{TBI}$ and $\mathrm{DM}$ foot ulcer were not statistically significant $(\mathrm{p}>0.05)$ between two groups (Table 2). Most patients (33.3\%) had a grade I ulcer in DF with DR group and $33.3 \%$ in DF without DR group (Figure 1).

Most of the patients $(86.7 \%)$ taking medication in DF with DR group and 30(100\%) in DF without DR group. Medication taking was significantly high patients who were DF without DR. Combined agents was 11(36.7\%) and $11(36.7 \%)$ in DF with DR and DF without DR group respectively. Insulin was taken $16(53.3 \%)$ in DF with DR group and 19(63.3\%) in DF without DR group (Table 3).

Table I: Socio-demographic characteristics of the patients $(\mathbf{n}=90)$

\begin{tabular}{|l|c|c|c|}
\hline Characteristics & $\begin{array}{c}\text { DF with } \\
\text { DR } \\
(\mathbf{n}=30)\end{array}$ & $\begin{array}{c}\text { DF } \\
\text { without } \\
\text { DR (n=30) }\end{array}$ & $\begin{array}{c}\text { P } \\
\text { value }\end{array}$ \\
\hline Age (years) & $56.6 \pm 9.3$ & $54.8 \pm 10.1$ & 0.381 \\
\hline Sex (Male) & $34(72.3 \%)$ & $29(67.4 \%)$ & 0.612 \\
\hline $\begin{array}{l}\text { Diabetes duration } \\
\text { (year) }\end{array}$ & $18.7 \pm 10.3$ & $13.4 \pm 8.7$ & 0.010 \\
\hline History of HTN & $23(76.6 \%)$ & $22(73.3 \%)$ & 0.799 \\
\hline Blood pressure (mmHg) & \multicolumn{3}{|l|}{} \\
\hline Systolic & $131.6 \pm 18.6$ & $127.6 \pm 19.0$ & 0.315 \\
\hline Diastolic & $70.2 \pm 10.4$ & $69.8 \pm 11.1$ & 0.860 \\
\hline BMI (kg/m²) & $22.9 \pm 3.7$ & $23.1 \pm 3.5$ & 0.793 \\
\hline History of smoking & $10(33.3 \%)$ & $12(40 \%)$ & 0.328 \\
\hline
\end{tabular}

DF-Diabetic foot, DR-Diabetic retinopathy

$\mathrm{P}$ value was done from Student's t-test as shown mean $\pm \mathrm{SD}$ and Chi square test as shown categorical variables
Table II: Biochemical characteristics of the patients $(\mathrm{n}=60)$

\begin{tabular}{|c|c|c|c|}
\hline Characteristics & $\begin{array}{c}\text { DF with } \\
\text { DR } \\
(\mathbf{n}=30)\end{array}$ & $\begin{array}{c}\text { DF } \\
\text { without } \\
\text { DR }(n=30)\end{array}$ & $\begin{array}{c}\mathbf{P} \\
\text { value }\end{array}$ \\
\hline HbAlc (\%) & $8.1 \pm 1.7$ & $8.0 \pm 1.6$ & 0.775 \\
\hline $\begin{array}{l}\text { Preprandial glucose } \\
(\mathrm{mg} / \mathrm{dL})\end{array}$ & $149.7 \pm 87.3$ & $145.4 \pm 94.5$ & 0.823 \\
\hline C-peptide & $2.3 \pm 1.1$ & $1.9 \pm 1.4$ & 0.133 \\
\hline Insulin & $19.7 \pm 12.0$ & $33.2 \pm 23.7$ & 0.001 \\
\hline Cholesterol (mg/dL) & $150.5 \pm 42.3$ & $152.3 \pm 36.7$ & 0.830 \\
\hline Triglyceride $(\mathrm{mg} / \mathrm{dL})$ & $136.7 \pm 98.7$ & $137.3 \pm 66.3$ & 0.973 \\
\hline $\operatorname{HDL}(\mathrm{mg} / \mathrm{dL})$ & $38.9 \pm 11.4$ & $43.1 \pm 11.2$ & 0.081 \\
\hline $\mathrm{LDL}(\mathrm{mg} / \mathrm{dL})$ & $81.6 \pm 32.9$ & $82.2 \pm 33.1$ & 0.931 \\
\hline Hematocrit (\%) & $33.7 \pm 5.8$ & $35.9 \pm 5.2$ & 0.062 \\
\hline $\mathrm{BUN}(\mathrm{mg} / \mathrm{dL})$ & $31.3 \pm 16.3$ & $22.7 \pm 12.1$ & 0.005 \\
\hline \multicolumn{4}{|l|}{ Creatinine $(\mathrm{mg} / \mathrm{dL})$} \\
\hline $\mathrm{ABI}$ & $0.95 \pm 0.35$ & $0.96 \pm 0.30$ & 0.881 \\
\hline TBI & $0.57 \pm 0.28$ & $0.61 \pm 0.31$ & 0.521 \\
\hline \multicolumn{4}{|l|}{ DM foot ulcer } \\
\hline Grade I & $10(33.3 \%)$ & $10(33.3 \%)$ & 0.515 \\
\hline Grade II & $2(6.7 \%)$ & $5(16.7 \%)$ & \\
\hline Grade III & $8(26.7 \%)$ & $7(23.33 \%)$ & \\
\hline Grade IV & $9(30.0 \%)$ & $8(26.7 \%)$ & \\
\hline Grade V & $1(3.3 \%)$ & 0 & \\
\hline \multicolumn{4}{|c|}{ Diabetic retinopathy (DR) } \\
\hline No DR & 0 & $7(23.3 \%)$ & \\
\hline Mild NPDR & 0 & $5(16.7 \%)$ & \\
\hline Moderate NPDR & 0 & $11(36.7 \%)$ & 0.001 \\
\hline Severe NPDR & 0 & $7(23.3 \%)$ & \\
\hline PDR & $30(100 \%)$ & 0 & \\
\hline
\end{tabular}

DF-Diabetic foot, DR-Diabetic retinopathy

$P$ value was done from Student's t-test as shown mean \pm SD and Chi square test as shown categorical variables

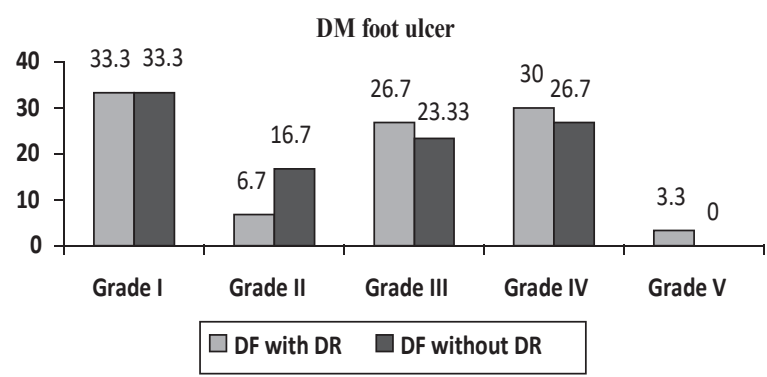

Figure 1: Bar diagram showing diabetes mellitus foot ulcer. 
Table III: Methods of glycemic control $(n=60)$

\begin{tabular}{|l|c|c|c|}
\hline $\begin{array}{l}\text { Methods of } \\
\text { glycemic } \\
\text { control }\end{array}$ & $\begin{array}{c}\text { DF with } \\
\text { DR } \\
(\mathbf{n}=30)\end{array}$ & $\begin{array}{c}\text { DF } \\
\text { without } \\
\text { DR (n=30) }\end{array}$ & $\begin{array}{c}\mathbf{P} \\
\text { value }\end{array}$ \\
\hline No medication & $4(13.3)$ & & 0.015 \\
\hline Medication & $26(86.7)$ & $30(100)$ & \\
\hline Combined agents & $11(36.7)$ & $11(36.7)$ & 0.918 \\
\hline Insulin & $16(53.3)$ & $19(63.3)$ & 0.357 \\
\hline
\end{tabular}

$\mathrm{P}$ value was done from Chi square test as shown categorical variables

\section{DISCUSSION}

The demographics for the population studied are likely to differ from those of the general outpatient diabetic population in several ways. It is likely to be an older population with a greater duration of diabetes, poor diabetic control, medical comorbidities and lower socioeconomic status. This was a major motivation for us to undertake this work.

In our study it was observed that the mean age was found 56.6 \pm 9.3 years in DF (Diabetic foot) with DR (Diabetic retinopathy) group and $54.8 \pm 10.1$ years in DF without DR group. In study of Hwang et al. ${ }^{6}$ observed that the mean age was found $66.7 \pm 8.8$ years in DFU with DR group and $66.8 \pm 12.6$ years in DFU without DR group. The difference was not statistically significant $(\mathrm{p}>0.05)$ between two groups. Girisha and Viswanathan ${ }^{1}$ study showed the mean age of the population in our study was 58.28 years \pm 11.36 . AlGoblan et al. ${ }^{7}$ study also reported that the aver冈age age of the patients included in the study was 56 years (standard deviation [SD] \pm 9.7 ).

In current study observed that Male was predominant in both groups $(73.3 \%$ vs $67.4 \%$ respectively). Mean duration of diabetes was significantly higher in DF with DR group $(\mathrm{p}<0.05)$. In this Hwang et al. ${ }^{6}$ male was found $75.0 \%$ in DF with DR group and $73.0 \%$ in DF without DR group. MrozikiewiczญRakowska et al. ${ }^{2}$ study observed that male was found $77.0 \%$ in DR group and $54.0 \%$ in control group. Girisha and Viswanathan ${ }^{1}$ study showed among the 145 cases studied, 95 (65.51\%) were males and $50(34.48 \%)$ were females with a male to female ratio of 1.9:1. Al Goblan et al. ${ }^{7}$ study revealed male found 59.3\% and female $40.7 \%$.

In this study mean duration of diabetes was found $18.7 \pm 10.3$ years in DFU with DR group and $13.4 \pm 8.7$ years in DF without DR group. Mean duration of diabetes was significantly higher in DFU with DR group $(\mathrm{p}<0.05)$. Similar observation was found different studies Hwang et al. showed that the mean duration of diabetes was found $20.6 \pm 10.4$ years in DFU with DR group and $15.8 \pm 10.3$ years in DF without DR group. The difference was statistically significant between two groups $(\mathrm{p}=0.022)$. Mrozikiewicz Rakowska et al. ${ }^{2}$ study showed the mean duration of diabetes was found $16.97 \pm 9.2$ years in DR group and $17.1 \pm 9.48$ years in control group. AlGoblan et al. ${ }^{7}$ study on the length of the disease, $45 \%$ of the patients had diabetes for ,10 years, $38.6 \%$ for $10-20$ years, and $16.4 \%$ for .20 years

In our study in both groups majority patients had history of HTN (76.6\% vs 73.3\%). Mean systolic and diastolic blood pressure and BMI were not statistically significant ( $p>0.05)$ between two groups. Mrozikiewicz冈Rakowska et al. ${ }^{2}$ study observed that the mean BMI was found $32.24 \pm 5.0 \mathrm{~kg} / \mathrm{m}^{2}$ in DR group and $30.24 \pm 5.42 \mathrm{~kg} / \mathrm{m}^{2}$ in control group. Hwang et al. study showed that history of HTN was found in $75.0 \%$ in DFU with DR group and 69.0\% in DFU without DR group. Mean blood pressure and BMI were not statistically significant $(P>0.05)$. History of smoking was found $10(33.3 \%)$ in DF with DR group and $12(40 \%)$ in DF without DR group. Which was not statistically significant $(\mathrm{p}>0.05)$ between two groups. Girisha and Viswanathan ${ }^{1}$ study showed hypertension was the most common among the associated comorbid illness. AlGoblan et al. ${ }^{7}$ the mean body weight of the patients was $81 \mathrm{~kg}(\mathrm{STD} \pm 13)$. BMI measurements showed that 12.9\% patients had normal BMI, whereas $30.7 \%$ were overweight and $56.4 \%$ were categorized as obese with BMI .30. None of the patients included in the study had underweight BMI.

In present study the mean insulin, BUN and diabetes retinopathy were statistically significant $(p<0.05)$ between two groups. Mean HbAlc, pre-prandial glucose, C-peptide, cholesterol, triglyceride, HDL, LDL, hematocrit, creatinine, $\mathrm{ABI}, \mathrm{TBI}$ and DM foot ulcer were not statistically significant ( $p>0.05$ ) between two groups. AlGoblan et al. ${ }^{7}$ study comparing patients with controlled highly elevated HbA1c, only $23 \%$ of patients had healed foot ulcers within 3 months, $28 \%$ between 3 and 6 months, and $48 \%>7$ months $(P=0.024)$. A similar association was observed between the process of healing and HbA1c levels in our patients. While studying the healing process in relation to HbAlc levels, we observed that $68 \%$ of patients with normal HbA1c had completely healed foot ulcers, whereas $20 \%$ showed partial healing 
and $4 \%$ had uncured foot ulcers. The remaining $8 \%$ of patients required graft placement. Among the patients with high HbAlc, 45.9\% showed complete heal『 ing, whereas $33.8 \%$ had partial healing, $5.4 \%$ progressed to grafting process, and $14.9 \%$ had unhealed foot ulcers. Hwang et al. ${ }^{6}$ study observed in terms of DR, 90 patients (90\%) had DR and 55 patients (55\%) had proliferative diabetic retinopathy (PDR). Eight patients (8\%) had mild non-proliferative diabetic retinopathy (NPDR) and 17 patients had moderate NPDR (17\%). Severe NPDR was observed in 10 patients $(10 \%)$.

In this study most patients (33.3\%) had a grade I ulcer in DF with DR group and 33.3\% in DF without DR group. Hwang et al. study observed that among 100 patients with DFUs, only one patient (1\%) had a grade 5 ulcer. Girisha and Viswanathan ${ }^{1}$ the number of patients with mild nonproliferative diabetic retinopathy were 95 (65.5\%) and those with moderate nonproliferative diabetic retinopathy were 45 (31.03\%). Severe nonproliferative diabetic retinopathy was seen in 5 patients who accounted for $3.44 \%$ of the total.

In this study Most of the patients (86.7\%) taking medication in DF with DR group and 30(100\%) in DF without DR group. Medication taking was significantly high patients who were DF without DR. Combined agents was $11(36.7 \%)$ and $11(36.7 \%)$ in DF with DR and DF without DR group respectively. Insulin was taken 16(53.3\%) in DF with DR group and 19(63.3\%) in DF without DR group. Hwang et al. was observed that no medication was found $10.0 \%$ in DFU with PDR group and medication used $90.0 \%$ in DFU with PDR group and $100 \%$ in DFU without PDR group. Combined oral agents was 35.0\% in DFU with PDR group and 36.0\% in DFU without PDR group. Insulin was $55.0 \%$ and $64.0 \%$ in DFU with PDR and DFU without PDR group respectively. The difference was not statistically significant ( $p>0.05)$ between two groups. Sharma et al. ${ }^{8}$ correlate the diabetic foot disease to the treatment history for the diabetes, the dreaded problem of diabetic foot was highest in patients who have not had any treatment (33.64\%), followed by insulin users $(21.99 \%)$, and then followed by oral hypoglycemic agents (14.43\%). Surprisingly, another study has shown insulin to be a known risk factor diabetic foot disease. ${ }^{9}$ Perhaps untreated patients were left out in this study.

\section{CONCLUSIONS}

Maximum patients had a grade I ulcer in diabetes foot ulcer. Medication taking was significantly high patients who were diabetes foot ulcer than without diabetes foot ulcer. Mean insulin, BUN and diabetic retinopathy was found statistically significantly higher in diabetes with diabetes foot ulcer.

\section{REFERENCES}

1. Girisha BS, Viswanathan N. In search of cutaneous marker for retinopathy in diabetic patients: A pilot study. Clin Dermatol Rev 2017; 1: 52-5.

2. Mrozikiewicz\Rakowska B, Łukawska M, Nehring P, Szymański K, Agnieszka Sobczyk】 Kopcioł A, Krzyżewska M, et al. Genetic predictors associated with diabetic retinopathy in patients with diabetic foot. Pol Arch Intern Med. 2018; 128 (1): 35-42

3. Kovarik JJ, Eller AW, Willard LA, et al. Prevalence of undiagnosed diabetic retinopathy among inpatients with diabetes: the diabetic retinopathy inpatient study (DRIPS). BMJ Open Diabetes Research and Care 2016;4: e000164.

4. Klein R, Klein B. Vision disorders in diabetes. In: National Diabetes Data Group, ed. Diabetes in America. 2nd edn. Bethesda, MD: National Institutes of Health, National Institute of Diabetes and Digestive and Kidney Diseases, 1995:293-337.

5. Aziz KMA. Association between high risk foot, retinopathy And hbalc in saudi diabetic population. Pak J Physiol 2010;6(2):22-28

6. Hwang DJ, Lee KM, Park MS, Choi Sh, Park JI, Cho JH, et al. (2017) Association between diabetic foot ulcer and diabetic retinopathy. PLoS ONE 12(4): e0175270

7. AlGoblan AS, Alrasheedi IM, Basheir OH, Haider $\mathrm{KH}$. Prediction of diabetic foot ulcer healing in type 2 diabetic subjects using routine clinical and laboratory parameters. Research and Reports in Endocrine Disorders 2016:6 11-16

8. Sharma R, Kapila R, Sharma AK, Mann J. Diabetic Foot Diseas-Incidence and risk factors: A Clinical Study. J Foot Ankle Surg (Asia-Pacific) 2016; 3(1): 41-46.

9. Boyko EJ, Ahroni JH, Stensel V, Forsberg RC, Davignon DR, Smith DG. A prospective study of risk factors for diabetic foot ulcer: The Scattle Diabetic Foot Study. Diabetes Care 1999; 22(7): 1036-4. 